\title{
Gender gap in medical research: a bibliometric study in Swiss university hospitals
}

\author{
Paul Sebo $^{1}$ (D) Sylvain de Lucia ${ }^{2} \cdot$ Nathalie Vernaz $^{3}$
}

Received: 16 July 2020 / Published online: 29 October 2020

(c) The Author(s) 2020

\begin{abstract}
Several studies explored gender inequalities in research, but only limited data are available concerning general internal medicine and family medicine. We aimed to assess the level of gender inequalities in Swiss academic medical research. In this bibliometric study conducted in March 2020, we selected all senior hospital physicians practicing internal medicine or family medicine in the six Swiss university hospitals. The list of these physicians was extracted from the hospitals' websites. We recorded their socio-demographic characteristics. Then, using Web of Science, we retrieved the number of publications (overall, as first author, per year, per year as first author), the proportion of publications as first author, the number of citations (overall, per year, per publication) and the $h$-index, and we compared the data by gender. 367 senior physicians were included in the study [female physicians: 172 (47\%), internal medicine: 187 (51\%)]. Female physicians were four times less likely to be a professor $(5 \%$ vs. $20 \%, p$ value $<0.001)$ and half as often heads of division or staff physicians $(19 \%$ vs. $40 \%, p$ value $<0.001)$. The proportion of physicians having published at least one article was lower among women than men $(79 \%$ vs. $90 \%, p$ value 0.003). Finally, all bibliometric indices were associated with male gender (incident rate ratios ranging from 1.9 [(95\% CI 1.3-2.8), $p$ value 0.001$]$ for number of citations per publication to 9.3 [(95\% CI 5.3-16.2), $p$ value $<0.001]$ for number of citations), except the proportion of publications as first author that was associated with female gender [odds ratio 1.7 (95\% CI 1.2-2.3), $p$ value 0.003). Our data suggest a "leaky pipeline" phenomenon (a lower proportion of women moving up the academic ladder). In addition, with the exception of the proportion of publications as first author, all bibliometric indices were lower for female than male physicians.
\end{abstract}

Keywords Gender gap · Female physician · Medical research $\cdot$ General internal medicine · Family medicine $\cdot$ Switzerland $\cdot$ Bibliometric study $\cdot$ Publications $\cdot$ Citations $\cdot h$-Index

Paul Sebo

paulsebo@hotmail.com

1 Primary Care Unit, University of Geneva, Geneva, Switzerland

2 Department of Community Health and Medicine, Geneva University Hospital, Geneva, Switzerland

3 Medical and Quality Directorate, Geneva University Hospital, Geneva, Switzerland 


\section{Background}

In the last decades, we have seen a major shift in the medical profession, with an increasing proportion of women doctors, even in disciplines that were previously largely dominated by males, such as surgery (Filardo et al. 2016; Allen 2005). Despite this positive development, gender inequalities persist in the academic environment and become particularly pronounced when looking at senior positions (Allen 2005; Rexrode 2016; Bernard 2018; Diamond et al. 2016; Holman et al. 2018).

These inequalities are caused by multiple factors. In addition to family reasons, including inequalities in the time devoted to domestic responsibilities and career breaks for maternal leaves, women often face major obstacles throughout their academic careers (Bates et al. 2016; Ashmos Plowman and Smith 2011). For the same level of responsibility, their salaries are often lower than those of men, they have more difficulties in funding and publishing their research, and generally have slower and more erratic career progression than their male counterparts (Bates et al. 2016; Ashmos Plowman and Smith 2011).

Publication of research is crucial, not only because it disseminates scientific knowledge but also because it increases the recognition of researchers (Rexrode 2016; Vale 2015; Bavdekar and Tullu 2016; Post et al. 2012). The productivity of researchers has become a common variable used to measure the performance of researchers in most fields, including medicine (Pfeiffer et al. 2016; Prpić 1996). The publication of scientific articles obviously plays a crucial role in the process of promotion and career advancement. There is no doubt that gender inequalities in this field are one of the main factors contributing to the major disequilibrium between male and female physicians in senior positions in university hospitals.

Several studies explored gender inequalities in research, mostly assessing the publication of scientific articles in various medical fields, but little data exist for general biomedical journals. A recent bibliometric study that included 767 randomly selected articles published in 2016 in high impact factor journals of family medicine $(n=9)$ and internal medicine $(n=9)$ found that the female authorship proportion was, overall, $48 \%$ but with notable differences by medical specialty (63\% for family medicine and $33 \%$ for internal medicine) (Sebo et al. 2020). Since these studies focused primarily on the analysis of articles published in medical journals, we thought it useful to address the theme of gender inequalities in research by focusing on researchers who publish rather than on published articles.

The objective of our study was to assess the level of gender inequalities in research in Swiss academic medical centers. To do this, we searched the publications of all senior hospital physicians practicing internal medicine or family medicine in the six Swiss university hospitals. The study focused on bibliometric indicators, mainly the number of publications, the number of citations and the $h$-factor. We hypothesized higher indices among male researchers. 


\section{Methods}

\section{Study site and study population}

This bibliometric study was carried out between 1 and 14 March 2020 in the six Swiss university hospitals (Geneva, Lausanne, Bern, Basel, Zurich and Fribourg). We selected all senior hospital physicians (heads of division, staff physicians and senior registrars) practicing internal medicine or family medicine. There were no exclusion criteria. The list of these physicians was extracted from the hospitals' websites.

\section{Data collection}

We recorded their socio-demographic characteristics (name, gender, medical department, academic rank [professor $(\mathrm{Y} / \mathrm{N})$ ]), position [head of division, staff physician, senior registrar, other (consulting physician, senior research physician, senior education physician)].

Then, using the citation report function of Web of Science, we extracted their bibliometric data (number of publications, number of publications as first author, year of first publication, number of citations, $h$-index). In addition to the number of publications and citations, the $h$-index has become relatively popular for measuring researcher productivity because it takes better account of both the productivity and impact of researchers' publications (Hirsch 2005). This index is defined as the number of papers $h$ that were each cited at least $h$ times. The year of first publication (i.e. the year of publication of the first article) was chosen to evaluate the career length.

The list of publications was obtained for all years up to the survey by using the following search criteria: "all databases" and "search by author, select from index", and by entering the surname and first name in the search box. For physicians with two surnames, we searched with the two surnames separated by a space, the two surnames separated by a hyphen, and with each of the two surnames. For physicians with two first names, we used the first one. Extraction was carried out by two investigators (PS and NV). All data were double-checked to exclude any errors. Before extracting the data we removed articles published by homonyms (doubts about certain publications were resolved by discussion within the study team).

\section{Statistical analyses and sample size}

We created five new bibliometric variables. The number of publications per year was computed by dividing the number of publications by the number of years since the publication of the first article. The number of publications per year as first author was obtained by dividing the number of publications as first author by the number of years since the publication of the first article. The number of citations per year was computed by dividing the number of citations by the number of years since the publication of the first article. The number of citations per publication was obtained by dividing the number of citations by the number of publications. These four variables were rounded to the nearest unit. Finally, the proportion of publications as first author was computed by dividing the number of publications as first author by the total number of publications. 
We used frequency tables to describe sociodemographic characteristics (=categorical variables), and medians and interquartile ranges (IQRs) to summarize bibliometric data (=non-normal variables).

We compared the data by gender using Chi square tests for sociodemographic characteristics and Wilcoxon rank-sum tests or univariate negative binomial regressions for all bibliometric data (=count data with over-dispersion) except for the proportion of publications as first author (=proportion). (Negative Binomial Regression 2019a; b) For this variable, its values ranging between 0 and 1, we used a generalized linear model (glm) with the logit link, the binomial family, and the robust option to obtain robust standard errors (Papke and Wooldridge 1996; Stata 2020).

We also carried out multivariable analyses to adjust the results for sociodemographic characteristics (number of years since the publication of the first article grouped into six categories, location, department and academic rank) using multivariable negative binomial regressions for all bibliometric data except for the proportion of publications as first author. For this variable, as we did for the univariable analysis, we used a generalized linear model. As planned within the study team, we decided to include these sociodemographic variables in the multivariable model, because they are theoretically important and might be significant confounders in the association we observed between the risk factor (gender) and the outcome (bibliometric variables).

Using the sample size determination for negative binomial regression, we estimated that by comparing two groups (male and female physicians), a sample of 343 would be sufficient to detect a difference of five publications with type I and II error both set at $5 \%$. We expected the average number of publications to be 10 for male physicians and 5 for female physicians, the ratio of the number of participants to be 0.75 and the dispersion parameter to be five (Zhu and Lakkis 2014). We performed all statistical analyses with STATA version 15.1 (College Station, USA).

\section{Results}

A total of 367 senior physicians were included in the study, of whom 172 (47\%) were women. Table 1 summarizes their socio-demographic characteristics. Slightly more than half of the physicians were located in Western Switzerland (Geneva and Lausanne). Half of them were affiliated to a department of family medicine and were senior registrars. Overall, $13 \%$ were professors. Female physicians were four times less often professors and half as often heads of division or staff physicians. Of the 367 physicians included in the study, $85 \%$ published at least one article $(N=312)$ with a majority of male physicians $(90 \%$ vs. $79 \%$ for females, $p$ value 0.003 ). Female physicians had published their first article more recently (median: 7 years vs. 11 years for men).

Table 2 presents physicians' bibliometric data, overall and stratified by gender. Their median number of publications and citations was 4 (IQR 26, min-max 0-510) and 12 (IQR 225, min-max 0-43201), respectively, and their median $h$-index was 1 (IQR 7, min-max 0-94). All indices were statistically significantly lower for female physicians compared to their male counterparts, with the exception of the proportion of publications as first author, which was $13 \%$ higher in absolute terms for females (median: $33 \%$ vs. $20 \%, p$ value $0.003)$. As the number of female professors in our sample was extremely low compared to their male counterparts, we repeated the analyses for professors only $(N=48)$. Gender differences remained, with p-values close to statistical significance: the median number of 
Table 1 Physicians' sociodemographic characteristics, overall and stratified by gender $(n=367)$

\begin{tabular}{lcccc}
\hline Characteristics & Total $(n=367)$ & $\begin{array}{l}\text { Female physicians } \\
(n=172) \\
N(\%)\end{array}$ & $\begin{array}{l}\text { Male physicians } \\
(n=195) \\
N(\%)\end{array}$ & $p$ value $^{\mathrm{a}}$ \\
\hline University hospital & $N(\%)$ & & & \\
Geneva & $134(36.5)$ & $72(41.9)$ & $62(31.8)$ & \\
Lausanne & $81(22.1)$ & $31(18.0)$ & $50(25.6)$ & \\
Bern & $49(13.3)$ & $26(15.1)$ & $23(11.8)$ & \\
Basel & $39(10.6)$ & $15(8.7)$ & $24(12.3)$ & \\
Zurich & $38(10.4)$ & $18(10.5)$ & $20(10.3)$ & \\
Fribourg & $26(7.1)$ & $10(5.8)$ & $16(8.2)$ & \\
Department & & & & \\
Family medicine & $180(49.0)$ & $87(50.6)$ & $93(47.7)$ & \\
Internal medicine & $187(51.0)$ & $85(49.4)$ & $102(52.3)$ & \\
Professor & & & $39(20.0)$ & \\
Yes & $48(13.1)$ & $9(5.2)$ & $156(80.0)$ & \\
No & $319(86.9)$ & $163(94.8)$ & $18(9.2)$ & \\
Hierarchical position & & & $61(31.3)$ & \\
Heads of division & $20(5.4)$ & $2(1.2)$ & $78(40.0)$ & \\
Staff physicians & $92(25.1)$ & $31(18.0)$ & $38(19.5)$ & \\
Senior registrars & $185(50.4)$ & $107(62.2)$ & $32(18.6)$ & \\
Other & $70(19.1)$ & &
\end{tabular}

${ }^{\mathrm{a}} \chi^{2}$ tests

${ }^{\mathrm{b}}$ Consulting physicians, senior research physicians and senior education physicians

publications was 50 (IQR 28) for female professors versus 96 (IQR 78) for male professors, $p$ value 0.05 ; the median number of citations 1117 (IQR 1486) versus 2234 (IQR 3405), $p$ value 0.08 ; and the median $h$-index 16 (IQR 10) versus 21 (IQR 19), $p$ value 0.07 . The only bibliometric index that was higher among women was, again, the median proportion of publications as first author: $20.5 \%$ (IQR 21.2) versus 17.0\% (IQR 13.1), but the difference was not statistically significant ( $p$ value 0.32 ).

Table 3 shows the measures of effect between bibliometric data and male gender in uniand multivariable analysis. In univariable analysis, all bibliometric indices were associated with male gender (incident rate ratios ranging from 1.9 to 9.3), except the proportion of publications as first author that was associated with female gender [odds ratio 1.7 (95\% CI $1.2-2.3), p$ value 0.003]. In multivariable analysis, all bibliometric variables were associated with male gender, except the proportion of publications as first author [the association with female gender was close to statistical significance: OR 1.4 (95\% CI 1.0-1.9), adjusted $p$ value 0.07 ] and the number of citations per publication [incident rate ratio IRR 0.9 (95\% CI 0.7-1.3), adjusted $p$ value 0.64]. Concerning the other variables, the IRRs ranged from 1.5 (for number of publications as first author and h-index) to 2.1 (for number of citations and number of citations per year). The results obtained were similar if we included in the multivariable analysis the academic rank [professor $(\mathrm{Y} / \mathrm{N})$ ] in addition to the other three socio-demographic factors ("Appendix").

Figures 1, 2 and 3 show physicians' number of publications, number of citations and $h$-index, by the number of years since the publication of their first article and gender. 


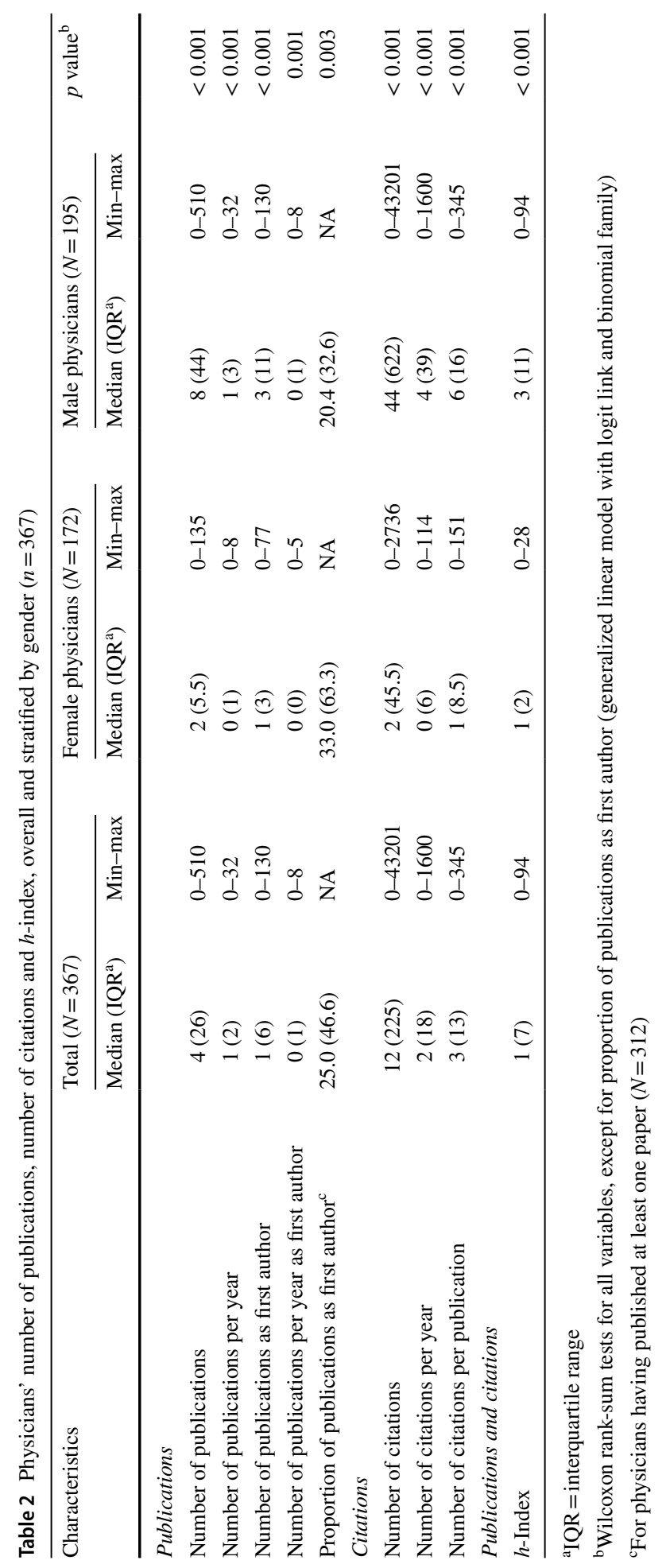




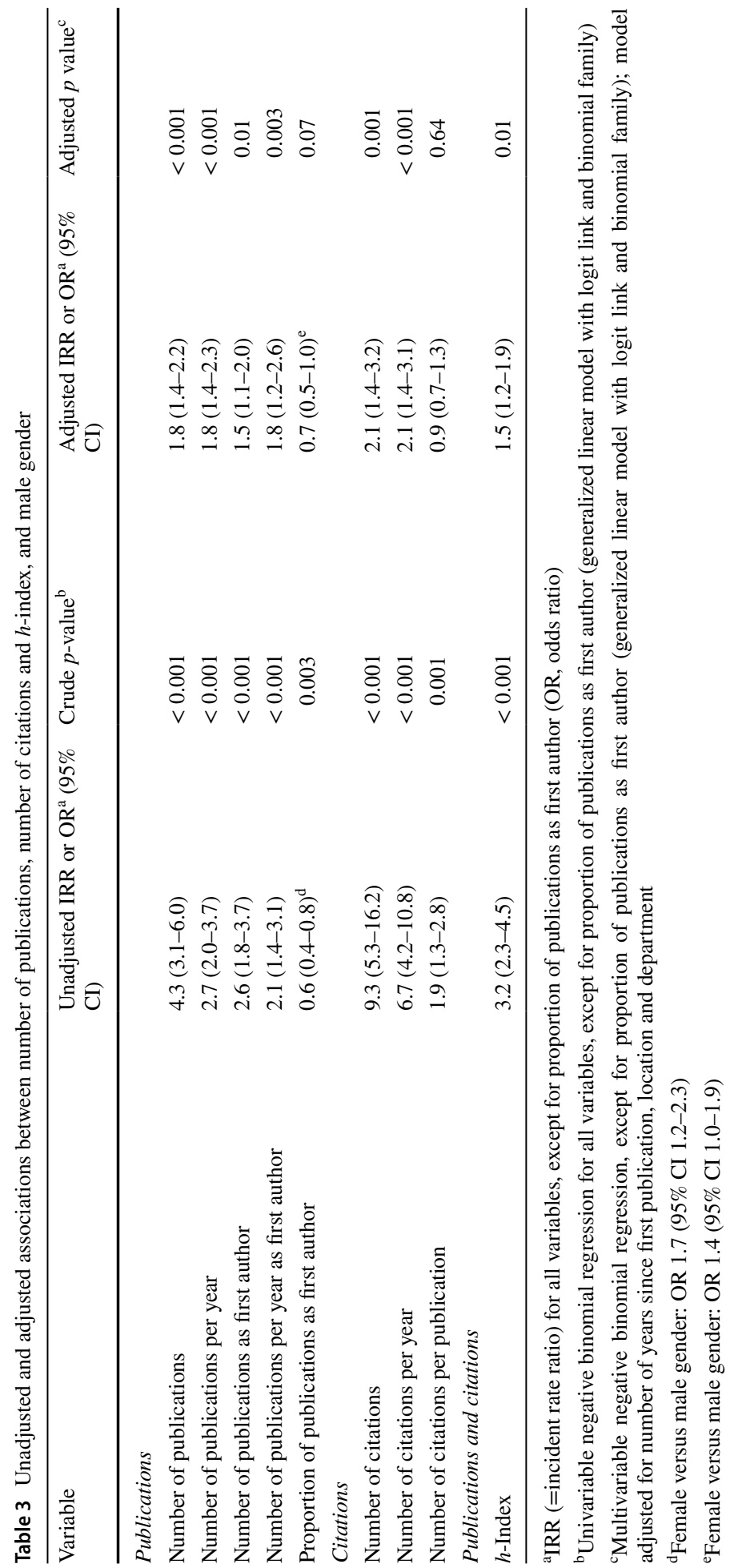




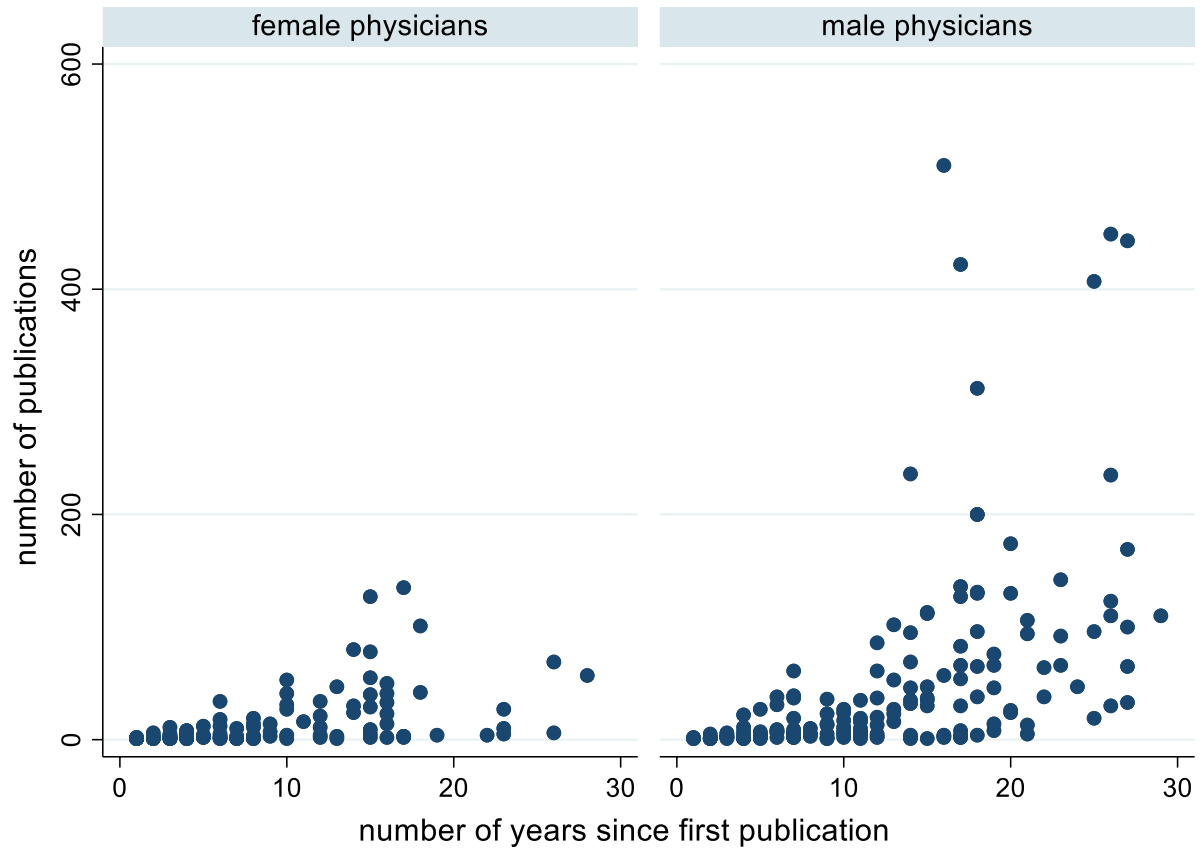

Fig. 1 Physicians' number of publications by number of years since first publication (data are shown separately for female and male physicians)

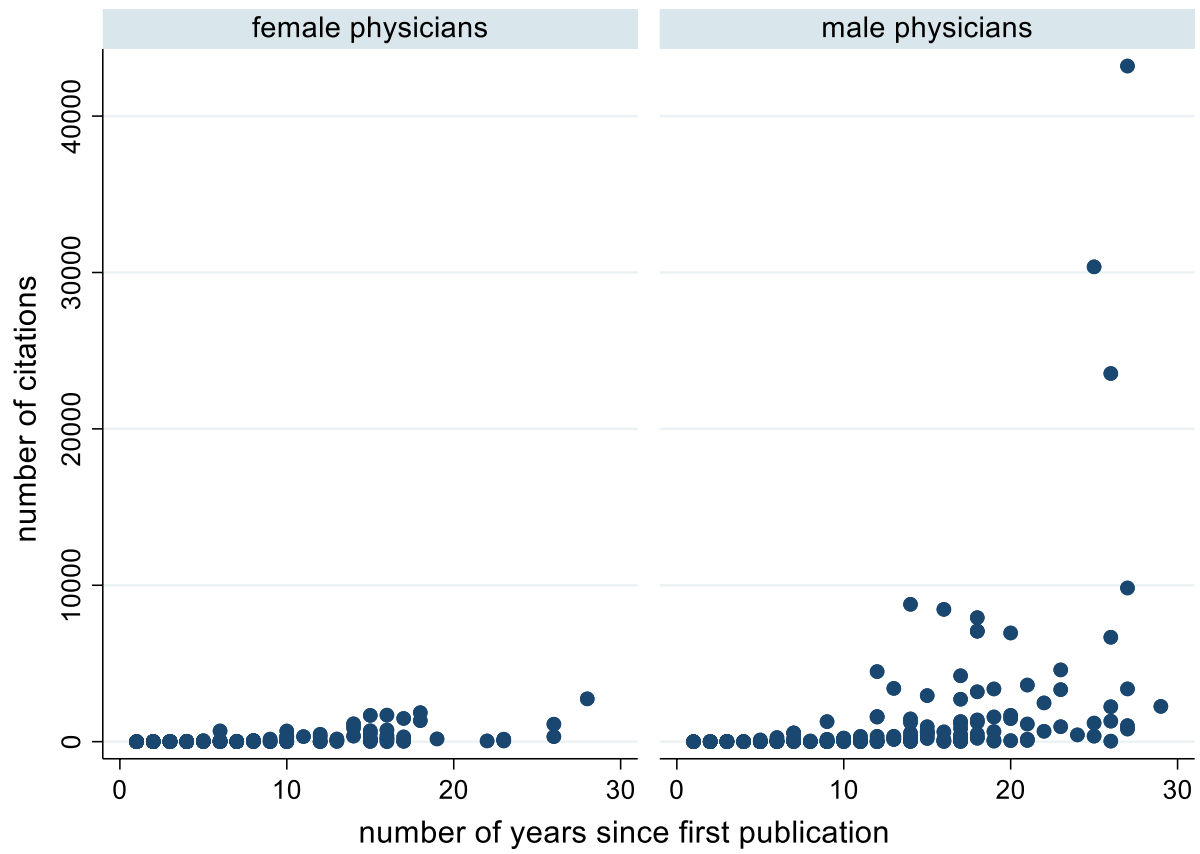

Fig. 2 Physicians' number of citations by number of years since first publication (data are shown separately for female and male physicians) 


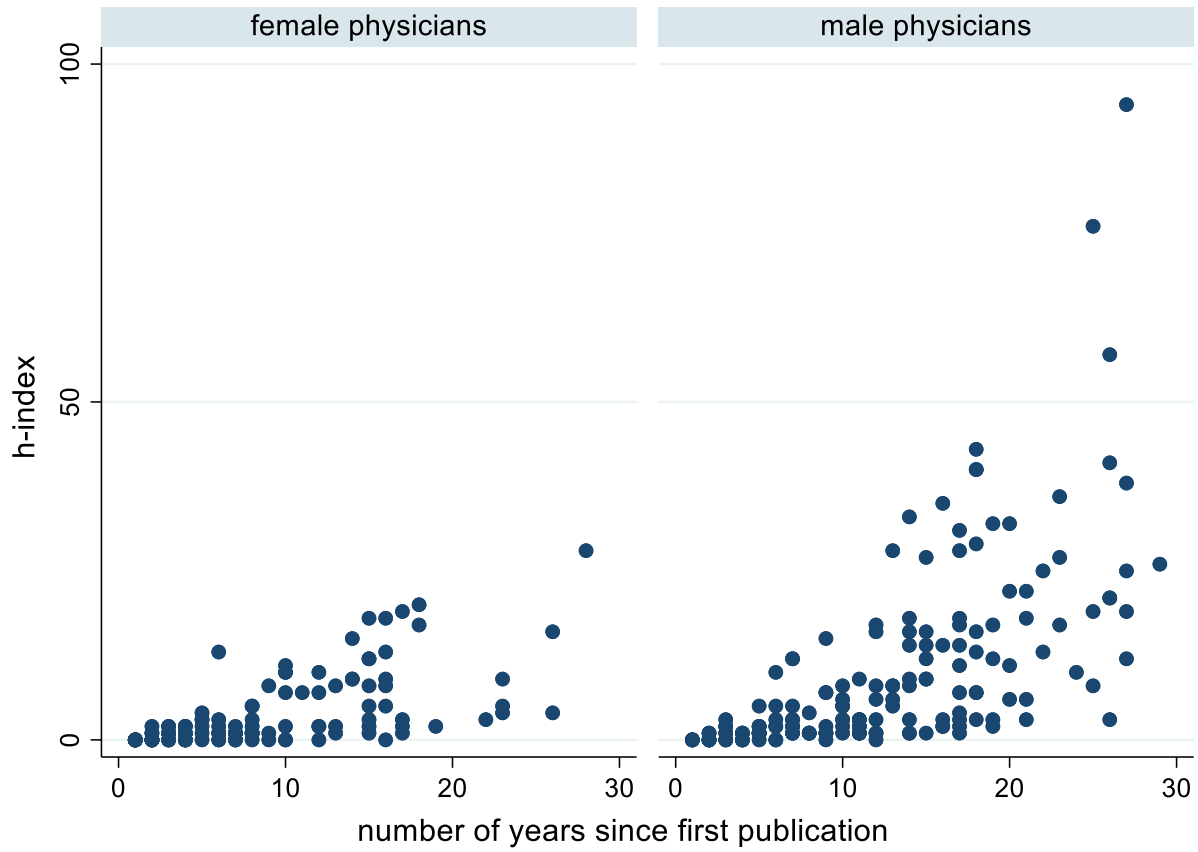

Fig. 3 Physicians' $h$-index by number of years since first publication (data are shown separately for female and male physicians)

For all three variables, the differences between male and female physicians increased with the number of years since their first article was published.

\section{Discussion}

\section{Main findings}

In this sample comprising all senior physicians practicing internal medicine or family medicine in the university hospitals in Switzerland, we found that, compared to male physicians, their female counterparts were four times less often professors and half as often heads of division or staff physicians. We also found that the proportion of senior physicians having published at least one article was $10 \%$ lower in absolute value for women than for men. Finally, we found that all bibliometric indices were associated with male gender, with the exception of the proportion of publications as first author (this variable was associated with female gender in univariable analysis and the 
association was close to statistical significance in multivariable analysis) and the number of citations per publication (in multivariable analysis).

\section{Comparison with existing literature}

Several studies assessed the degree of gender inequality in academic medicine, mainly by examining the proportion of women in senior positions and the proportion of female authors in scientific publications (Larivière et al. 2013; Bendels et al. 2018; Feramisco et al. 2009; Fishman et al. 2017). Various forms of discrimination occurring in the careers of female scientists prevent them from reaching the highest positions or hinder their academic progression (Kalaitzi et al. 2019a, b; Ramakrishnan et al. 2014; Carr et al. 2002). Although the number of female physicians outreaches that of their male counterparts at the outset, they become increasingly rare in the course of a scientific career. This phenomenon has been called the "leaky pipeline" (Carr et al. 2002; Swiss Medical Weekly 2020). Our data suggest as well that a lower proportion of women move up the academic ladder: $62 \%$ of female physicians were senior registrars (compared to $40 \%$ of male physicians), but only $18 \%$ were staff physicians (vs. 31\%) and $1 \%$ were heads of division (vs. 9\%).

Regarding scientific publications, there is little data about authors' gender to our knowledge for journals in internal medicine or family medicine. According to a study by Filardo et al. the proportion of women among the first authors (female first authorship) of six highimpact biomedical journals (Annals of Internal Medicine, Archives of Internal Medicine, BMJ, JAMA, Lancet, NEJM) was 37\% in 2014 (Filardo et al. 2016). Another study by Jagsi et al. showed that this proportion was $29 \%$ in 2004 in six high-impact journals, including NEJM, JAMA and Annals of Internal Medicine (Jagsi et al. 2006). A third study by Schrager et al. that targeted family medicine journals (Family Medicine, Journal of Family medicine, Journal of the American Board of Family Medicine, Annals of Family Medicine, and American Family Physician) found that the female first authorship was 34\% between 2006 and 2008 (Schrager et al. 2011). Finally, a study having included 767 randomly selected articles published in 2016 in high impact factor journals of family medicine $(n=9)$ and internal medicine $(n=9)$ found that the overall proportion of female first authorship was $48 \%$, but that the proportion varied considerably from one journal category to another (63\% for primary health care journals and $33 \%$ for internal medicine journals) (Sebo et al. 2020).

Our study addressed gender inequalities by focusing on the productivity of researchers. We included in the study all senior physicians practicing internal medicine or family medicine in the six university hospitals in Switzerland. Our study identified a clear gender gap as the aforementioned studies. Taking into account confounding factors, we showed that women published on average half as many articles as men. As shown in Fig. 1, the gender differences, which were minimal at the beginning, gradually increased over the course of a medical career.

Interestingly, although female physicians published less than their male counterparts they were more often the first author (proportion of publications as first author: $33 \%$ vs. $20 \%$ ). The difference was statistically significant in univariable analysis and close to statistical significance in multivariable analysis. Several studies showed an uneven gender distribution across authorship places, which is probably linked to women underrepresentation 
in leadership positions. In these studies, compared to men, women were relatively overrepresented at first but underrepresented at last authorship place (Fishman et al. 2017; Long et al. 2015; Bendels et al. 2017; Dotson 2011). Last authors in biomedical sciences are generally more likely to be in senior positions in research teams. Senior authorship is correlated with academic advancement and frequently used as a career evaluation metric (Bendels et al. 2017). Our finding of a gender gap in first authorship might therefore reflect the lower proportion of women among senior faculty members (except for first authorship, our study was not designed to examine the authorship position). Alternatively, this relatively high percentage of women among first authors could also mean that they are less likely to work or be involved in a research team. Here again, our data do not allow us to verify whether this assumption is correct.

However, this finding can also be interpreted in a more positive way, taking into account the number of citations, which, although lower in absolute numbers for female physicians, was similar in the two groups when examining the number of citations per publication. Indeed, these results suggest that women are able to invest time for their research projects and complete them, and that their publications are as useful for the scientific community as those of their male counterparts are.

The h-index, which is defined as the number of articles $h$ that were each cited at least $h$ times, and which is therefore a combined measure of the number of publications and citations, was about one-third lower for female than male physicians (incident rate ratio 1.5).

The number of female professors in our sample was extremely low compared to their male counterparts, which could explain in part the gender differences in the bibliometric indices. One might imagine that, compared to those with the title of professor, non-professor researchers would be more likely to be involved in routine or non-scientific tasks in their department, and less likely to collaborate in or be the instigator of a large number of studies. However, our results do not support this hypothesis, the gender differences remained whether we limited our analyses to professors only. Furthermore, the results of the multivariable analysis were not modified by the adjustment for academic rank (professor yes/no).

\section{Socio-cultural perspective}

Gender inequality in academic medicine is a complex and evolving issue (Kalaitzi et al. 2019a, b; Reed and Buddeberg-Fischer 2001). Socio-cultural factors such as work-family balance preferences are likely to have a major influence on gender differences in scientific productivity (Kalaitzi et al. 2019a, b; Ramakrishnan et al. 2014; Lachish et al. 2016). Indeed, the balance that some women create between their career and family aspirations makes it difficult for them to devote the time necessary to their academic work. In addition, some forms of gender based discrimination are still occurring in academic medicine and are changing the academic trajectories of women (Bates et al. 2016; Kalaitzi et al. 2019a, b; Ramakrishnan et al. 2014).

In addition to combating stereotypes and discrimination, various strategies could be implemented to try to reduce gender inequalities in academic research. Possible strategies include providing strong role models for female researchers and promoting flexible working hours, developing curricula aiming to an optimal work-private life balance and working on the establishment of alternative indicators to evaluate academic careers. 


\section{Limitations}

Some limitations need to be kept in mind when considering our results. First, the study sample consisted only of physicians practicing internal medicine or family medicine in the six Swiss university hospitals. The findings cannot necessarily be generalized to other physicians or researchers in Switzerland, or to other countries. Second, the risk of errors in publication lists cannot be completely excluded, even though we standardized search procedures and duplicated all searches. In order to reduce this risk as much as possible, we reviewed all the publications of each physician included in the study. Doubts about certain publications (mainly articles that could have been authored by homonyms) were resolved by discussion within the study team. In addition, we preferred to retrieve physicians' publication lists using their first name spelled out in full. Even though this strategy probably reduced the risk of homonymy, we might have missed a few publications that were referenced without the full first name. Third, the data for the study were collected at only one point in time (March 2020). It would have been useful to collect data over several years in order to assess the evolution of the gender gap. Finally, this bibliometric study is limited by the absence of information concerning certain important socio-demographic characteristics, such as physicians' age.

\section{Conclusion}

In summary, in this sample comprising all senior physicians practicing internal medicine or family medicine in the six university hospitals in Switzerland, we found a lower proportion of women moving up the academic ladder (a phenomenon known as "leaky pipeline"). We also found that the proportion of senior physicians having published at least one article was $10 \%$ lower in absolute value for women than for men. Finally, we found that all bibliometric indices were associated with male gender, except the proportion of publications as first author that was associated with female gender.

Funding Open access funding provided by University of Geneva.

\section{Compliance with ethical standards}

Conflict of interest All authors declare that they have no conflict of interest.

Open Access This article is licensed under a Creative Commons Attribution 4.0 International License, which permits use, sharing, adaptation, distribution and reproduction in any medium or format, as long as you give appropriate credit to the original author(s) and the source, provide a link to the Creative Commons licence, and indicate if changes were made. The images or other third party material in this article are included in the article's Creative Commons licence, unless indicated otherwise in a credit line to the material. If material is not included in the article's Creative Commons licence and your intended use is not permitted by statutory regulation or exceeds the permitted use, you will need to obtain permission directly from the copyright holder. To view a copy of this licence, visit http://creativecommons.org/licenses/by/4.0/.

\section{Appendix}

See Table 4. 


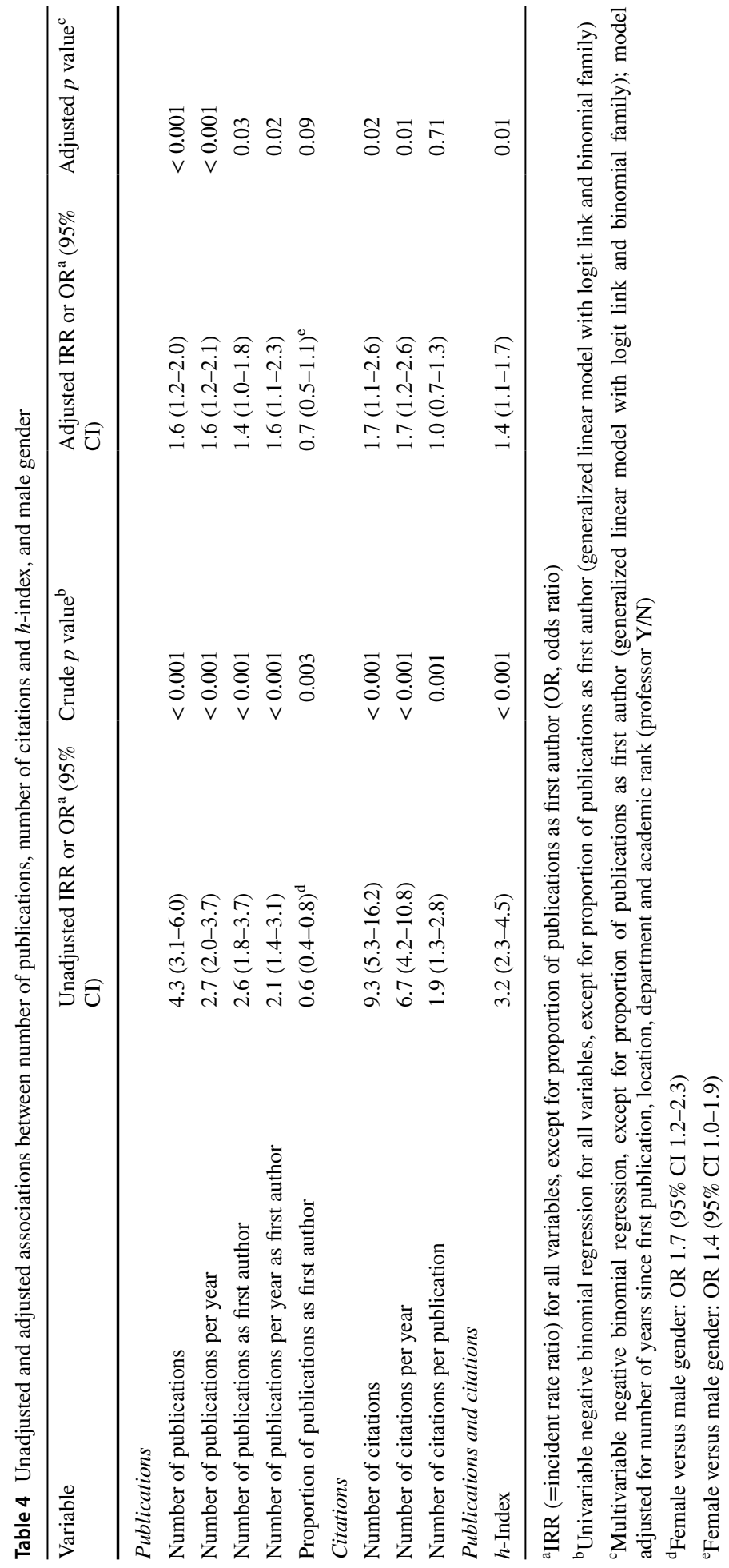




\section{References}

Allen, I. (2005). Women doctors and their careers: What now? BMJ, 331, 569-572.

Ashmos Plowman, D., \& Smith, A. D. (2011). The gendering of organizational research methods: Evidence of gender patterns in qualitative research. Qualitative Research in Organizations and Management is an International Journal, 6, 64-82.

Bates, C., Gordon, L., Travis, E., Chatterjee, A., Chaudron, L., Fivush, B., et al. (2016). Striving for gender equity in academic medicine careers: A call to action. Academic Medicine: Journal of the Association of American Medical Colleges, 91, 1050-1052.

Bavdekar, S. B., \& Tullu, M. S. (2016). Research publications for academic career advancement: An idea whose time has come. But is this the right way? Journal of Postgraduate Medicine, 62(1), 1-3.

Bendels, M. H. K., Brüggmann, D., Schöffel, N., \& Groneberg, D. A. (2017). Gendermetrics of cancer research: Results from a global analysis on lung cancer. Oncotarget, 8, 101911-101921.

Bendels, M. H. K., Dietz, M. C., Brüggmann, D., Oremek, G. M., Schöffel, N., \& Groneberg, D. A. (2018). Gender disparities in high-quality dermatology research: A descriptive bibliometric study on scientific authorships. BMJ Open, 8, e020089.

Bernard, C. (2018). Editorial: Gender bias in Publishing: Double-blind reviewing as a solution? Eneuro, $5(3)$.

Carr, P. L., Gunn, C. M., Kaplan, S. A., Raj, A., \& Freund, K. M. (2002). Inadequate progress for women in academic medicine: Findings from the National Faculty Study. Journal of Women's Health, 2015(24), 190-199.

Diamond, S. J., Thomas, C. R., Desai, S., Holliday, E. B., Jagsi, R., Schmitt, C., et al. (2016). Gender differences in publication productivity, academic rank, and career duration among US academic gastroenterology faculty. Academic Medicine, 91(8), 1158-1163.

Dotson, B. (2011). Women as authors in the pharmacy literature: 1989-2009. American Society of HealthSystem Pharmacists, 68, 1736-1739.

Feramisco, J. D., Leitenberger, J. J., Redfern, S. I., Bian, A., Xie, X.-J., \& Resneck, J. S. (2009). A gender gap in the dermatology literature? Cross-sectional analysis of manuscript authorship trends in dermatology journals during 3 decades. Journal of the American Academy of Dermatology, 60, 63-69.

Filardo, G., da Graca, B., Sass, D. M., Pollock, B. D., Smith, E. B., \& Martinez, M. A. M. (2016). Trends and comparison of female first authorship in high impact medical journals: Observational study (19942014). BMJ, 352.

Fishman, M., Williams, W. A., Goodman, D. M., \& Ross, L. F. (2017). Gender differences in the authorship of original research in pediatric journals, 2001-2016. The Journal of Pediatrics, 191(244-249), e1.

Hirsch, J. E. (2005). An index to quantify an individual's scientific research output. Proceedings of the National Academy of Sciences of the United States of America, 102, 16569-16572.

Holman, L., Stuart-Fox, D., \& Hauser, C. E. (2018). The gender gap in science: How long until women are equally represented? PLoS Biology, 16, e2004956.

Jagsi, R., Guancial, E. A., Worobey, C. C., Henault, L. E., Chang, Y., Starr, R., et al. (2006). The "gender gap" in authorship of academic medical literature-A 35-year perspective. The New England Journal of Medicine, 355, 281-287.

Kalaitzi, S., Cheung, K. L., Hiligsmann, M., Babich, S., \& Czabanowska, K. (2019a). Exploring women healthcare leaders' perceptions on barriers to leadership in greek context. Front Public Health, 7, 68.

Kalaitzi, S., Czabanowska, K., Azzopardi-Muscat, N., Cuschieri, L., Petelos, E., Papadakaki, M., et al. (2019b). Women, healthcare leadership and societal culture: A qualitative study. Journal of Healthcare Leadership, 11, 43-59.

Lachish, S., Svirko, E., Goldacre, M. J., \& Lambert, T. (2016). Factors associated with less-than-full-time working in medical practice: Results of surveys of five cohorts of UK doctors, 10 years after graduation. Human Resources for Health, 14, 62.

Larivière, V., Ni, C., Gingras, Y., Cronin, B., \& Sugimoto, C. R. (2013). Bibliometrics: Global gender disparities in science. Nature, 504, 211-213.

Long, M. T., Leszczynski, A., Thompson, K. D., Wasan, S. K., \& Calderwood, A. H. (2015). Female authorship in major academic gastroenterology journals: A look over 20 years. Gastrointestinal Endoscopy, 81(1440-1447), e3.

Negative Binomial Regression I Stata Annotated Output [Internet]. [Cited 2019 Nov 2]. Available from: https://stats.idre.ucla.edu/stata/output/negative-binomial-regression/.

Negative Binomial Regression I Stata Data Analysis Examples [Internet]. [Cited 2019 Nov 2]. Available from https://stats.idre.ucla.edu/stata/dae/negative-binomial-regression/.

Papke, L. E., \& Wooldridge, J. M. (1996). Econometric methods for fractional response variables with an application to 401(k) plan participation rates. Journal of Applied Econometrics, 11, 619-632. 
Pfeiffer, M., Fischer, M. R., \& Bauer, D. (2016). Publication activities of German junior researchers in academic medicine: Which factors impact impact factors? BMC Medical Education, 16, 190.

Post, R. E., Weese, T. J., Mainous, A. G., \& Weiss, B. D. (2012). Publication productivity by family medicine faculty: 1999 to 2009. Family Medicine, 44, 312-317.

Prpić, K. (1996). Characteristics and determinants of eminent scientists' productivity. Scientometrics, 36, 185-206.

Ramakrishnan, A., Sambuco, D., \& Jagsi, R. (2014). Women's participation in the medical profession: Insights from experiences in Japan, Scandinavia, Russia, and Eastern Europe. Journal of Women's Health, 23, 927-934.

Reed, V., \& Buddeberg-Fischer, B. (2001). Career obstacles for women in medicine: An overview. Medical Education, 35, 139-147.

Rexrode, K. M. (2016). The gender gap in first authorship of research papers. BMJ, 352, i1130.

Schrager, S., Bouwkamp, C., \& Mundt, M. (2011). Gender and first authorship of papers in family medicine journals 2006-2008. Family Medicine, 43, 155-159.

Sebo, P., Maisonneuve, H., \& Fournier, J. P. (2020). Gender gap in research: A bibliometric study of published articles in primary health care and general internal medicine. Family Practice.

Stata I FAQ: Logit transformation [Internet]. [Cited 2020 Apr 23]. Available from https://www.stata.com/ support/faqs/statistics/logit-transformation/.

Swiss Medical Weekly-Op-eds-Challenging the "leaky pipeline" in faculties of medicine [Internet]. [Cited 2020 May 30]. Available from https://smw.ch/op-eds/post/challenging-the-leaky-pipeline-infaculties-of-medicine.

Vale, R. D. (2015). Accelerating scientific publication in biology. Proceedings of the National Academy of Sciences of the United States of America, 112, 13439-13446.

Zhu, H., \& Lakkis, H. (2014). Sample size calculation for comparing two negative binomial rates. Statistics in Medicine, 33, 376-387. 